\title{
Practical considerations in the pharmacological treatment of postherpetic neuralgia for the primary care provider
}

This article was published in the following Dove Press journal: Journal of Pain Research

10 March 2014

Number of times this article has been viewed

\section{Jamie S Massengill' \\ John L Kittredge ${ }^{2}$}

'JSM Medical, Edmond, OK, USA; 2Michiana Spine, Sports and Occupational Rehab, PC, Mishawaka, IN, USA
Correspondence: Jamie S Massengill JSM Medical, 7555 Winterwood Drive, Edmond, OK 73025, USA

$\mathrm{Tel}+$ I 4059905967

Fax +l 4052857546

Email jamie_massengill@yahoo.com
Abstract: An estimated one million individuals in the US are diagnosed with herpes zoster (HZ; shingles) each year. Approximately $20 \%$ of these patients will develop postherpetic neuralgia (PHN), a complex HZ complication characterized by neuropathic pain isolated to the dermatome that was affected by the $\mathrm{HZ}$ virus. PHN is debilitating, altering physical function and quality of life, and commonly affects vulnerable populations, including the elderly and the immunocompromised. Despite the availability of an immunization for $\mathrm{HZ}$ prevention and several approved HZ treatments, the incidence of PHN is increasing. Furthermore, management of the neuropathic pain associated with PHN is often suboptimal, and the use of available therapeutics may be complicated by adverse effects and complex, burdensome treatment regimens, as well as by patients' comorbidities and polypharmacy, which may lead to drug-drug interactions. Informed and comprehensive assessments of currently available pharmacological treatment options to achieve effective pain control in the primary care setting are needed. In this article, we discuss the situation in clinical practice, review currently recommended prevention and treatment options for PHN, and outline practical considerations for the management of this neuropathic pain syndrome, with a focus on optimal, individual-based treatment plans for use in the primary care setting.

Keywords: herpes zoster, postherpetic neuralgia, primary care, clinical practice, pharmacological treatment, practical guidelines

\section{Postherpetic neuralgia}

Postherpetic neuralgia (PHN), a neuropathic pain syndrome resulting from damage to nerve fibers, is the most common complication of herpes zoster (HZ; shingles), and the cause of the greatest HZ-related burden of illness. ${ }^{1-3} \mathrm{HZ}$ is a viral disease caused by the reactivation of varicella zoster virus (VZV) that had remained latent in sensory ganglia since the primary infection (chicken pox), and is characterized by a painful skin rash, usually limited to the area innervated by a single sensory ganglion (Figure 1).4,5 $\mathrm{PHN}$ is usually diagnosed in individuals who have recovered from the HZ skin rash but who have continued to experience pain for at least 3 months, although for some patients pain can persist for years. ${ }^{1-3,6}$

PHN pain occurs in the same dermatomes as the $\mathrm{HZ}$ rash, and is likely the result of damage to the nervous system (which may include deafferentation, peripheral and/or central sensitization, myelin destruction, inflammation, and signaling errors in the brain) that occurred during the proliferation and spread of the virus during the acute $\mathrm{HZ}$ infection. ${ }^{1,3,7}$ The syndrome has consequences permeating multiple aspects of patients' lives, affecting their sleep, concentration, and mood, as well as impacting 


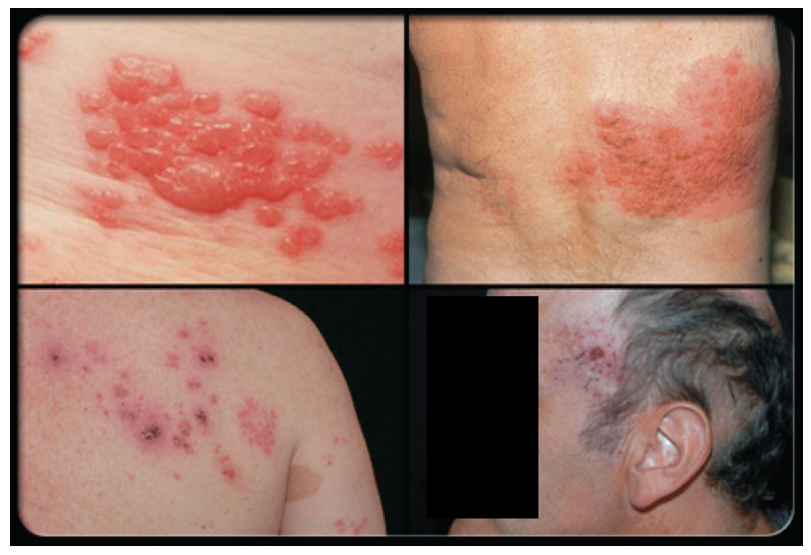

Figure I Herpes zoster (shingles) rash.

Notes: Herpes zoster (shingles) rash consists of painful skin blisters that erupt usually on only one side of the body along the distribution of a nerve on a single dermatome. Typically, this occurs along the chest, abdoment, back, or face, but it may also affect the neck, limbs, or lower back. @ 2005 The McGraw Hill Companies, Inc. Images from Wolff K, Johnson R, Fitzpatrick TB. Fitpatrick's color atlas and synopsis of clinical dermatology. 5th Ed. New York; McGraw-Hill Education; 2005. ${ }^{66}$

their physical functionality by interfering with activities of daily living. ${ }^{8,9}$

As many as $20 \%$ of patients with HZ develop PHN. Major risk factors include advanced age and decreased immunity., ${ }^{1,10-12}$ Approximately half of all PHN cases occur in persons older than 60 years. Therefore, the incidence of $\mathrm{HZ}$ and risk of $\mathrm{PHN}$ is likely to increase as the population ages. ${ }^{13,14}$ The declining cell-mediated VZV immunity from immune senescence also contributes to the observed increased prevalence of PHN in the elderly. ${ }^{15,16}$ Finally, the severity of the acute HZ infection and the presence of a notable prodrome have also been associated with increased likelihood of experiencing PHN. ${ }^{1,10-12}$

\section{Practical considerations for management of PHN}

For primary care providers, PHN may not present as a distinct entity but rather an extension of the original $\mathrm{HZ}$ infection, and monitoring for a global condition affecting multiple aspects of patients' lives rather than for a localized post-HZ pain is paramount. Thus, practical management of PHN can be divided into prevention and treatment of HZ, and the more challenging task of managing the neuropathic pain syndrome and its consequences once PHN has developed (Figure 2). ${ }^{17,18}$

To date, no cure for PHN exists, only treatments that are palliative and that may shorten the duration and severity of the pain. Therefore, vaccinations to prevent initial chicken pox and thus VZV from ever gaining a foothold in the body in the first place, or vaccinations to prevent reactivation of VZV

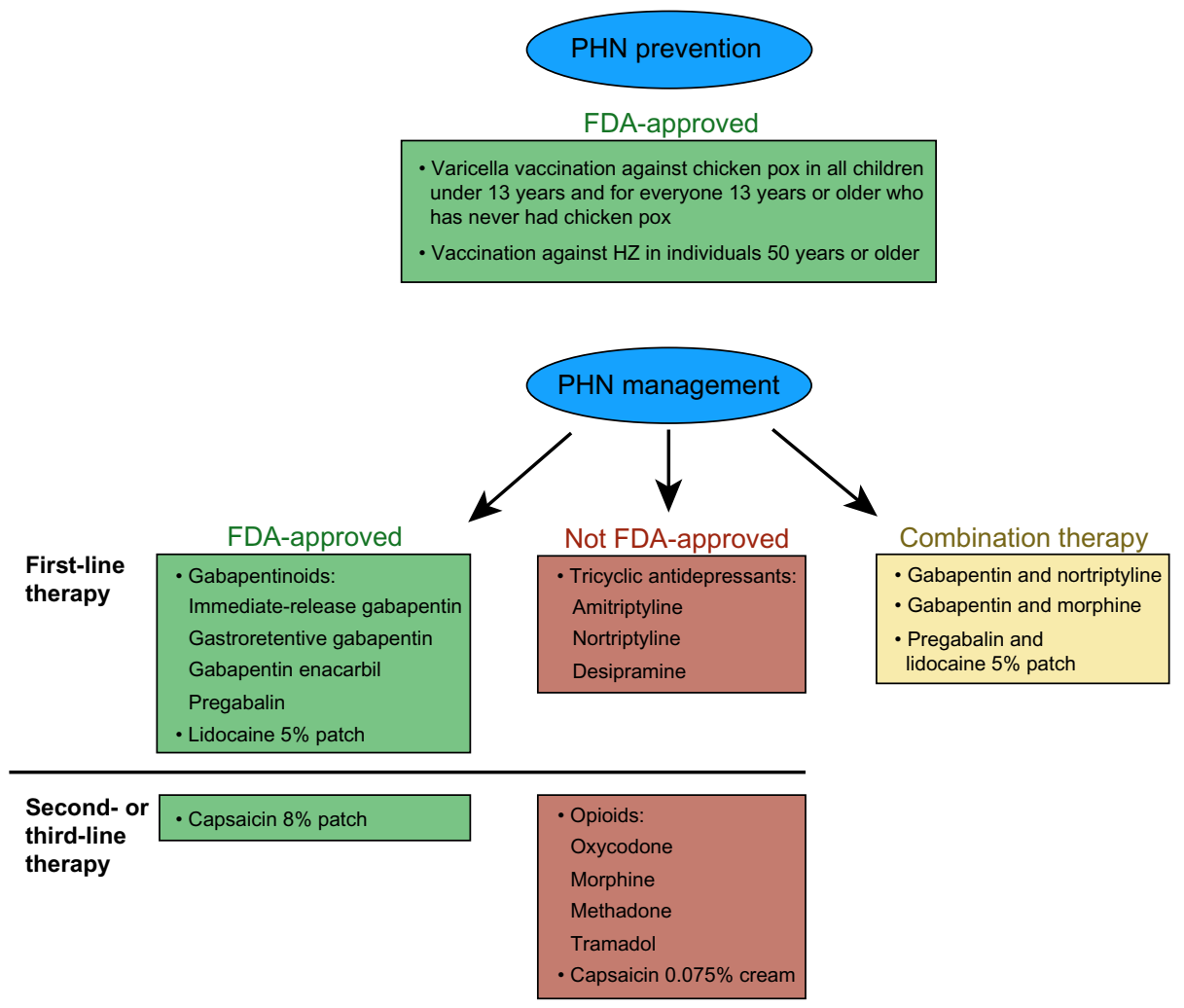

Figure 2 Current postherpetic neuralgia (PHN) prevention and treatment options. Abbreviations: FDA, US Food and Drug Administration; HZ, herpes zoster (shingles). 
already present in the body remain a priority; however, there are uncertainties about the vaccines' duration of protection and/or how frequently booster can be given. ${ }^{19-21}$ For patients who were exposed to VZV and who contracted acute HZ, the primary care provider may use antivirals, analgesics, or corticosteroids to decrease acute pain and possibly decrease the risk of developing PHN. ${ }^{17,22,23}$

Despite the availability of vaccination, a communication gap between primary medical providers and patients hinders satisfactory prevention of VZV and HZ. PHN incidence is on the rise, the effective management of PHN remains an ongoing challenge, and no single best therapy has yet been identified. ${ }^{24,25}$ Current guidelines for management of PHN pain recommend gabapentinoids (gabapentin and pregabalin), tricyclic antidepressants (TCAs), opioids, topical agents, and combination therapies with different mechanisms of action (Figure 2). ${ }^{26-28}$ However, the US Food and Drug Administration (FDA) has only approved four oral systemic medications, all of which are gabapentinoids, and two topical analgesics specifically for the management of pain associated with PHN (Figure 2).

A carefully devised, individually based treatment plan is critical to ensure optimal outcomes in the management of PHN. Pain and its interference with daily activities are subjective symptoms and difficult to manage effectively, even more so in older patients, who are predominantly afflicted with PHN, and who are more likely to have multiple chronic health issues and declining function and frailty. ${ }^{29,30}$ A significant number of patients who develop chronic pain associated with $\mathrm{PHN}$ do not receive evidence-based, recommended treatment modalities, leaving many patients undertreated and dissatisfied with the treatment. ${ }^{24,31,32}$ To ensure optimal results, the initial choice of PHN pain therapy should be guided not only by drug efficacy but also by the patient's comorbidities, severity of PHN pain, the drugs' adverse-event and drug-interaction profiles, titration regimen, and patient preference, especially since no single therapy has demonstrated superior effectiveness. Because $\mathrm{PHN}$ is a complex condition and should not be simplified to a localized area of pain, the most practical therapeutic approach may involve a systemic medication or combination therapy rather than topical analgesics alone. Finally, clear communication with the patient and frequent monitoring of adverse reactions and patient satisfaction with the treatment should be established.

Adverse effects can be a major limiting factor for many therapies. TCAs have anticholinergic adverse effects, and may cause balance problems and cognitive impairment in elderly patients. ${ }^{33,34}$ In addition, the recently published update of the Beers criteria by the American Geriatrics Society ${ }^{35}$ identified TCAs as a class of drugs to avoid in older adults. Elderly patients treated with opioid analgesics can experience mobility problems, increased risk of hip fracture, and cognitive impairment. ${ }^{30,33,36}$ Also, given the complexity of opioid management, the American Pain Society and American Academy of Pain Medicine have suggested cautious initiation and titration of opioids in frail older persons or those with comorbidities. ${ }^{37}$ Gabapentinoids have a better safety profile than other oral therapeutics, although they can be associated with high incidence of dizziness, swelling, confused thinking, and somnolence.

Other factors, such as titration and treatment regimen, drug interactions, drug efficacy, and modes of administration or application, can also limit the use of several PHN treatment options. Topical agents, especially the lidocaine 5\% patch, have a favorable safety profile, but they can be impractical for PHN involving the head and face, can have a burdensome application regimen (ie, capsaicin cream and patch), and can be ineffective as a monotherapy. Gabapentinoids can have complex and burdensome titration schedules often based on three-times-daily dosing. Among new formulations, gastroretentive gabapentin can simplify the patient's daily medication burden, improve patient acceptance and compliance with simpler once-daily dosing, and lower incidence of adverse events compared with other gabapentinoids. Furthermore, both topical lidocaine patches and gabapentinoids are good candidates for combination therapy, due to their low propensity for interactions with other drugs.

\section{PHN prevention}

\section{Vaccination}

With continued widespread use of varicella vaccine Varivax $^{\circledR}$; Merck, Whitehouse Station, NJ, USA) ${ }^{38}$ in childhood, primary medical providers may expect to prevent initial VZV infection (chicken pox) and subsequent HZ (shingles) later in life, but varicella vaccine failed to provide long-term protection from VZV. ${ }^{19}$ One approach to the prevention of PHN in those already harboring VZV involves the administration of the $\mathrm{VZ}$ vaccine (Zostavax ${ }^{\circledR}$; Merck), which has been approved by the FDA for individuals 50 years of age or older. ${ }^{39}$ The Zostavax ${ }^{\circledR}$ vaccine, which activates specific T-cell production and thus prevents viral reactivations, was found to be effective in reducing the burden of illness due to HZ, incidence of HZ, and incidence of PHN, and was well tolerated, with minor systemic and injection-site adverse events. ${ }^{20,40,41}$ However, despite the promising results of immunization, data 
are still insufficient to support long-term prevention of $\mathrm{HZ}$ and PHN, and similarly to varicella vaccine, the zoster vaccine protection my wane over time. ${ }^{18,20,21,42}$ Also, the vaccine remains widely underused, mainly due to the surprising lack of vigilant recommendation by primary care providers as well as lack of awareness of $\mathrm{HZ}$ and the $\mathrm{HZ}$ vaccine. ${ }^{43,44}$

\section{Treatment of $\mathrm{HZ}$}

Although still controversial, early treatment of $\mathrm{HZ}$ with antiviral agents may decrease the risk of developing or duration of PHN. ${ }^{45}$ Three antiviral agents are approved in the US for the treatment of HZ: acyclovir (Zovirax ${ }^{\circledR}$; GlaxoSmithKline, Brentford, UK), famciclovir (Famvir ${ }^{\circledR}$; Novartis Pharmaceuticals Corporation, East Hanover, NJ, USA), and valacyclovir (Valtrex ${ }^{\circledR}$; GlaxoSmithKline). ${ }^{46-48}$ To limit the amount of viral replication and reduce the duration of the HZ rash, antivirals should be administered within 72 hours of rash onset. ${ }^{49}$ They may be beneficial as long as new lesions are actively being formed, which is important to note, since in clinical practice the diagnosis of $\mathrm{HZ}$ is rarely made within 72 hours. However, the safety and efficacy of antivirals in treating $\mathrm{HZ}$ or preventing PHN more than 72 hours after rash onset have not been established. ${ }^{46-48}$

Antivirals alone are not sufficient to relieve the acute pain associated with HZ. Mild-to-moderate pain can be controlled with a short-acting opioid with acetaminophen or a nonsteroidal anti-inflammatory agent, and gabapentinoids, followed by a TCA, can be added for more severe acute pain. Furthermore, the combination of gabapentin and valacyclovir administered acutely in patients with $\mathrm{HZ}$ may reduce the incidence of $\mathrm{PHN} .{ }^{50}$ Although not recommended routinely for treatment of $\mathrm{HZ}$ and most likely ineffective in preventing PHN, corticosteroids are often considered in clinical practice for $\mathrm{HZ}$ patients with limited contraindications. ${ }^{17,22,23,51}$

\section{PHN management}

\section{Therapies approved by the FDA}

\section{Oral therapies}

Gabapentinoids (also known as calcium channel $\alpha 2-\delta$ ligands) are the only oral medications to date approved by the FDA for the management of PHN, and they are an effective and one of the most commonly used first-line therapies for chronic PHN pain (Figure 2). As gabapentinoids are excreted by the kidneys, dosages should be adjusted according to creatinine clearance in patients with renal impairment.

For immediate-release gabapentin (generic gabapentin or Neurontin ${ }^{\circledR}$; Pfizer, New York, NY, USA), three-timesdaily dosing is recommended (Table 1). ${ }^{52}$ Although in clinical practice, alternate dosing may be prescribed, the recommended number of daily doses should not be exceeded. The most effective therapeutic dosage of immediate-release gabapentin is $1,800 \mathrm{mg} / \mathrm{day},{ }^{53}$ while additional benefit of using greater dosages was not demonstrated, and long titration times to reach this optimal dosage may be required. ${ }^{52}$ A retrospective study of medical claims revealed patients took on average 10 weeks to reach $1,800 \mathrm{mg}$ /day immediaterelease gabapentin, and only $14 \%$ of patients reached the target dosage. ${ }^{54}$ Immediate-release gabapentin has been associated with a relatively high rate of adverse events $(28 \%$ of patients reported dizziness and $21 \%$ of patients reported somnolence in clinical trials). ${ }^{52}$

Treatment with immediate-release gabapentin may be inadequate, due to intolerable drug side effects, long titration periods to reach therapeutic dosages, and low compliance with frequent daily dosing. To improve the efficacy, safety, and tolerability of PHN therapy through simplified dosing regimens and shorten titration periods, two extended-release formulations of gabapentin were developed and recently approved by the FDA for the treatment of PHN: gastroretentive gabapentin (Gralise $^{\circledR}$; Depomed, Newark, CA, USA), approved in 2011, ${ }^{55}$ and gabapentin enacarbil (Horizant ${ }^{\circledR}$; XenoPort, Santa Clara, CA, USA), approved in $2012^{56}$ (Table 1). The dosing regimen for gastroretentive gabapentin is reduced to once daily, and a majority of patients (over 90\%) reach therapeutic dosage within 2 weeks. ${ }^{57}$ Gabapentin enacarbil is dosed twice daily with a 4-day to 1 -week titration period. ${ }^{58}$ Neither of these new formulations was directly compared to the immediate-release gabapentin, but gastroretentive gabapentin was associated with fewer adverse events in clinical trials (11\% for dizziness and $5 \%$ for somnolence), ${ }^{55}$ while similar incidence of adverse events was reported for gabapentin enacarbil (22\% for dizziness and $27 \%$ for somnolence). ${ }^{55,56}$

Pregabalin (Lyrica ${ }^{\circledR}$; Pfizer) is a successor to immediaterelease gabapentin, approved for the treatment of PHN in $2005 .^{59}$ It is dosed two or three times a day and requires a 1-week titration (Table 1), although a retrospective study of medical claims revealed patients required 5-9 weeks to reach therapeutic dosages. ${ }^{59}$ In clinical trials, pregabalin was associated with slightly higher rates of adverse events than immediaterelease gabapentin (approximately 29\% of patients reported dizziness and $18 \%$ of patients reported somnolence). ${ }^{59}$

\section{Topical therapies}

Two FDA-approved topical therapies are available for PHN treatment: the lidocaine 5\% patch (Lidoderm ${ }^{\circledR}$; Endo, Chadds Ford, PA, USA $)^{60}$ as a first-line therapy, and the capsaicin $8 \%$ patch (Qutenza ${ }^{\circledR}$; Acorda Therapeutics, Ardsley, NY, USA) ${ }^{61}$ as a second-line therapy (Figure 2). The lidocaine 5\% patch 
Table I Recommended dosages and side effects of medications for treating postherpetic neuralgia (PHN) pain

\begin{tabular}{|c|c|c|}
\hline Therapy & Dosage & Most common adverse effects \\
\hline \multicolumn{3}{|l|}{ Gabapentinoids } \\
\hline Gabapentin & $\mathrm{I}, 800-3,600 \mathrm{mg} /$ day, three times a day, variable titration & \multirow{4}{*}{$\begin{array}{l}\text { Dizziness, somnolen } \\
\text { diarrhea, dry mouth; } \\
\text { of suicidal thoughts }\end{array}$} \\
\hline Gastroretentive gabapentin & I,800 mg once daily, 2-week titration & \\
\hline Gabapentin enacarbil & I,200 mg/day, twice daily, 4-day to I-week titration & \\
\hline Pregabalin & $150-600 \mathrm{mg} /$ day, two or three times a day; I-week titration & \\
\hline \multicolumn{3}{|l|}{ Tricyclic antidepressants } \\
\hline Nortriptyline & Up to 150 mg/day; multiple daily dosing; variable titration & \multirow{3}{*}{$\begin{array}{l}\text { Cardiotoxicity (arrhythmias, heart block, } \\
\text { myocardial infarction), anxiety, confusion, } \\
\text { sedation, blurred vision, dry mouth, constipation, } \\
\text { urinary retention; warning for increased risk of } \\
\text { suicidal thoughts }\end{array}$} \\
\hline Desipramine & & \\
\hline Amitriptyline & & \\
\hline \multicolumn{3}{|l|}{ Opioids } \\
\hline Oxycodone & Variable dosage and titration; no maximum dosage indicated, & \multirow{5}{*}{$\begin{array}{l}\text { Constipation, nausea, vomiting, anorexia, } \\
\text { seizure threshold decreased, sedation, dizziness, } \\
\text { confusion, dependence }\end{array}$} \\
\hline Morphine & but morphine equianalgesic dosages exceeding $120 \mathrm{mg} /$ day are & \\
\hline Methadone & not recommended; convert to long-acting opioid as needed & \\
\hline & when pain becomes chronic (for patients requiring therapy for & \\
\hline & few weeks) and continue short-acting agent as needed & \\
\hline Tramadol & 100-400 mg/day, multiple daily dosing, variable titration & \\
\hline \multicolumn{3}{|l|}{ Topical agents and creams } \\
\hline Lidocaine $5 \%$ patch & Up to three patches per day & $\begin{array}{l}\text { Application-site mild reactions (erythema, } \\
\text { pruritus) }\end{array}$ \\
\hline Capsaicin 8\% patch & $\begin{array}{l}\text { Up to four patches for I hour every } 3 \text { months or longer; } \\
\text { needs to be administered by a physician or trained personnel; } \\
\text { a topical anesthetic is applied to the affected area before } \\
\text { capsaicin patch }\end{array}$ & $\begin{array}{l}\text { Application-site reactions (pain, burning, } \\
\text { erythema, pruritus, papules) }\end{array}$ \\
\hline Capsaicin $0.075 \%$ cream & $3-5$ times per day & \\
\hline
\end{tabular}

provides modest pain relief for some patients in comparison to oral therapies, but it has a favorable safety and tolerability profile (Table 1). The capsaicin $8 \%$ patch has shown only minimal analgesic efficacy in patients with PHN. ${ }^{18}$ Initial pain during treatment with the capsaicin patch is a significant problem, and topical anesthetic is recommended before application. Also, the capsaicin $8 \%$ patch needs to be administered by or under close supervision of a medical provider or trained personnel, as capsaicin is a highly irritant material. ${ }^{61}$

\section{Therapies not approved by the FDA Oral therapies}

Tricyclic antidepressants

Although not approved by the FDA, TCAs have been commonly used for the treatment of pain associated with PHN since the early 1980s. Amitriptyline, nortriptyline, and desipramine are antidepressants currently recommended as first-line therapies (Figure 2). Clinical experience indicates that TCAs can be efficacious in relieving neuropathic pain, although they display a relatively slow onset of action, and the medical literature shows that they do not work as well in patients with certain types of pain common in PHN (ie, burning pain or allodynia). ${ }^{18,62}$ TCAs are often poorly tolerated, and are associated with significant systemic adverse events and cardiac toxicity (Table 1), which require considerable caution when treating older patients, the population that is the most prevalent for developing PHN. Amitriptyline is the most widely prescribed TCA, but desipramine and nortriptyline are associated with fewer side effects. ${ }^{18,33,63}$

\section{Opioids}

Natural and synthetic opioids (eg, oxycodone, morphine, methadone, and tramadol) are used in PHN management, although they are not approved by the FDA for that indication (Figure 2). They are available as fast-acting (2-6 hours of analgesia) or as long-acting (8-24 hours of analgesia). Great concern exists regarding the risks of side effects, the possibility of misuse, and potential for abuse or diversion associated with opioids, and they have been recommended as a secondline therapy for the treatment of pain associated with PHN (Table 1). ${ }^{18}$ Also, patients will develop physical dependence, and opioid analgesics must be used cautiously.

\section{Topical therapy}

Similarly to the capsaicin $8 \%$ patch, over-the-counter capsaicin $0.075 \%$ cream has shown minimal analgesic effect in patients with PHN, and it is recommended as a second- or 
third-line therapy (Figure 2). ${ }^{18}$ Initial pain during treatment with capsaicin cream, which has to be applied multiple times daily, is the leading cause of treatment discontinuations. ${ }^{64}$

\section{Combination therapies}

A single drug is not capable of modifying all of the complex pain mechanisms that underlie PHN, and thus may not provide sufficient pain relief. Consequently, the use of at least two therapies with different, complementary mechanisms of action that target multiple sites along the PHN pain pathway (Figure 2) may result in better analgesia. ${ }^{27,28}$ In addition, it may be important to consider how therapeutics act on the ascending spinothalamic pain pathway (which communicates from the body to the brain, initiating the conscious realization of pain) or the descending corticospinal pain pathway (which communicates from the brain to the body, inhibiting pain). For example, there is logic to using gabapentin to calm the ascending pain pathway and decrease pain, and TCAs to enhance the descending pathway and modulate pain, or to using gabapentin and the topical lidocaine patch, which both affect the ascending pain pathway, with gabapentin affecting central sensitization and lidocaine affecting peripheral sensitization.

The most attractive agents for combination therapies are gabapentinoids and topical analgesics, due to their low propensity for interactions with other drugs. ${ }^{52,55,56,59-61}$ The combination of pregabalin and the lidocaine 5\% patch was effective in patients with PHN who did not previously respond to either medication as monotherapy, and the treatment was generally well tolerated, with most adverse events attributed to pregabalin. ${ }^{18}$ Clinical studies suggest that gabapentin combined with nortriptyline or morphine yields better reduction in PHN pain than either agent alone. ${ }^{18}$ The rate of adverse events was not higher for combined therapies than for monotherapies in clinical studies, but the rate of drug-specific adverse events remained high, especially for the TCA and opioid. ${ }^{18}$

\section{Clinical practice}

Primary care is essential and frequently the front line in the diagnosis and treatment of PHN. Drug costs and insurance plans are an unfortunate reality in clinical practice, and are often major considerations and limiting factors in the management of PHN. Thus, because of cost, generic immediate-release gabapentin is often the first-choice medication. Unfortunately, the most effective dosage of $1,800 \mathrm{mg} /$ day is frequently not attained, ${ }^{54}$ which may leave patients undertreated. This may occur because treatment is terminated if any adverse events occur, or because in their attempt to avoid such adverse events as dizziness and somnolence, practitioners are tentative in the titration regimen they use. Although in certain patients, significant reductions in pain can be achieved at immediate-release gabapentin dosages lower than 1,800 mg/day, regular evaluations are crucial to ensure these patients continue to receive an adequate therapeutic response with lower dosages over time.

With failure of generic immediate-release gabapentin, other formulations of gabapentin are usually considered (most insurance plans will cover gastroretentive gabapentin or pregabalin). At this point, the most optimal choice should be based not just on costs but also on the profile of adverse events and ease of titration. The lidocaine 5\% patch may be used in combination with any gabapentinoid for better management of pain, although it is expensive. The lidocaine $5 \%$ patch seems a better choice than the capsaicin $8 \%$ patch, which is not only expensive but also painful and not practical, as its application takes several hours of medical providers' and patients' time. Patients who have failed attempts at treatment may be referred to a specialty pain practice, where the approach is often to retry medications at lower dosages to avoid adverse events, or to get patients to therapeutic dosages to evaluate whether they had a true therapeutic failure or an inadequate trial leading to unsuccessful treatment. However, only a small proportion of patients suffering from PHN consult specialty care, so many of them remain undertreated and dissatisfied with the treatment. Thus, the ideal therapeutic approach may be better utilization of available treatment options and careful evaluation of PHN management at the level of primary care.

As the Patient Protection and Affordable Care Act is being implemented, a sizable physician shortage is predicted, and physician assistants and nurse practitioners are predicted to fill the gap in primary care. ${ }^{65}$ Therefore, more mid-level providers may coordinate the acute treatment of HZ in urgent-care settings or primary care offices, and they will be responsible for the surveillance and management of PHN. PHN is a complex condition, is difficult to treat, and requires a methodical therapeutic approach, and physician assistants and nurse practitioners are critical in coordinating team-based and patient-centered care.

\section{Conclusion}

Optimal management of pain in PHN patients is complex and difficult. Although there are several therapeutic options, PHN treatment is often inadequate, leaving patients undertreated. Better utilization of available options and multimechanistic 
approaches to PHN management based on the patient's individual characteristics may be the most beneficial. Primary care plays a crucial role in the development and implementation of the PHN treatment plan, and establishing effective communication with patients. Well-devised and well-executed PHN therapy will not only ensure sufficient pain relief but will also facilitate improvements in patients' physical and psychosocial functions.

We conducted a comprehensive literature search for peer-reviewed articles about HZ and PHN using the PubMed search engine and relevant Medical Subject Headings $(\mathrm{MeSH})$ terms and keywords. Identified studies included those that evaluated the treatment of $\mathrm{HZ}$ and/or PHN in terms of efficacy and safety. The same search was repeated for review articles, including meta-analyses and systematic reviews. Additional searches included bibliographies of the retrieved articles, and Medline searches using the names of authors who had published several articles on $\mathrm{HZ}$ or PHN. We first reviewed titles and abstracts for relevance, and selected articles were then reviewed on their entirety. Included articles were English-language studies, addressed epidemiology and burden of HZ, were prospective or retrospective studies that provided clinical information on treated patients, provided detailed methodology and clear outcome measures, demonstrated treatment/prevention of $\mathrm{HZ}$ or PHN as a primary purpose, and described treatments feasible for an outpatient setting approved by the FDA or adhering to current guidelines on the care of PHN patients. ${ }^{26-28}$ Studies and reviews that included other conditions were only included if results were reported separately for each condition. Studies that described case reports or case series were excluded.

\section{Acknowledgment}

Iwona Bucior, $\mathrm{PhD}$ of Depomed Inc., provided medical writing support.

\section{Disclosure}

The authors report no conflicts of interest in this work.

\section{References}

1. Watson P. Postherpetic neuralgia. Am Fam Physician. 2011;84(6): 690-692.

2. Tontodonati M, Ursini T, Polilli E, et al. Post-herpetic neuralgia. Int $J$ Gen Med. 2012;5:861-871.

3. Harpaz R, Nagel MA, Schmader K, Tyring SK, Yawn BP. Roundtable on postherpetic neuralgia - what, why, how long, and what's next? Popul Health Manag. 2012;15(6):385-390.

4. Frisch S, Guo AM. Diagnostic methods and management strategies of herpes simplex and herpes zoster infections. Clin Geriatr Med. 2013;29(2):501-526.
5. Centers for Disease Control and Prevention. Shingles (herpes zoster) 2011. Available from: http://www.cdc.gov/shingles/about. Accessed January 15, 2014.

6. Reda H, Greene K, Rice FL, Rowbotham MC, Petersen KL. Natural history of herpes zoster: late follow-up of 3.9 years $(\mathrm{n}=43)$ and 7.7 years $(\mathrm{n}=10)$. Pain. 2013;154(10):2227-2233.

7. Baron R. Mechanisms of postherpetic neuralgia - we are hot on the scent. Pain. 2008;140(3):395-396.

8. Pickering G, Leplege A. Herpes zoster pain, postherpetic neuralgia, and quality of life in the elderly. Pain Pract. 2011;11(4):397-402.

9. Drolet M, Brisson M, Levin MJ, et al. A prospective study of the herpes zoster severity of illness. Clin J Pain. 2010;26(8):656-666.

10. Weaver BA. Herpes zoster overview: natural history and incidence. J Am Osteopath Assoc. 2009;109 Supp1 2:S2-S6.

11. Jung BF, Johnson RW, Griffin DR, Dworkin RH. Risk factors for postherpetic neuralgia in patients with herpes zoster. Neurology. 2004;62(9):1545-1551.

12. Opstelten W, Zuithoff NP, van Essen GA, et al. Predicting postherpetic neuralgia in elderly primary care patients with herpes zoster: prospective prognostic study. Pain. 2007;132 Suppl 1:S52-S59.

13. Christensen K, Doblhammer G, Rau R, Vaupel JW. Ageing populations: the challenges ahead. Lancet. 2009;374(9696):1196-1208.

14. US Census Bureau. National population projection summary tables. 2012. Available from: http://www.census.gov/prod/2011 pubs/12statab/ pop.pdf. Accessed January 15, 2014.

15. Bennett GJ, Watson CP. Herpes zoster and postherpetic neuralgia: past, present and future. Pain Res Manag. 2009;14(4):275-282.

16. Johnson RW. Herpes zoster and postherpetic neuralgia: a review of the effects of vaccination. Aging Clin Exp Res. 2009;21(3):236-243.

17. Gan EY, Tian EA, Tey HL. Management of herpes zoster and postherpetic neuralgia. Am J Clin Dermatol. 2013;14(2):77-85.

18. Harden RN, Kaye AD, Kintanar T, Argoff CE. Evidence-based guidance for the management of postherpetic neuralgia in primary care. Postgrad Med. 2013;125(4):191-202.

19. Goldman GS, King PG. Review of the United States universal varicella vaccination program: herpes zoster incidence rates, cost-effectiveness, and vaccine efficacy based primarily on the Antelope Valley Varicella Active Surveillance Project data. Vaccine. 2013;31(13):1680-1694.

20. Drolet M, Oxman MN, Levin MJ, et al. Vaccination against herpes zoster in developed countries: state of the evidence. Hum Vaccin Immunother. 2013;9(5):1177-1184.

21. Bilcke J, Ogunjimi B, Hulstaert F, Van Damme P, Hens N, Beutels P. Estimating the age-specific duration of herpes zoster vaccine protection: a matter of model choice? Vaccine. 2012;30(17):2795-2800.

22. Fashner J, Bell AL. Herpes zoster and postherpetic neuralgia: prevention and management. Am Fam Physician. 2011;83(12):1432-1437.

23. Thakur R, Philip AG. Chronic pain perspectives: treating herpes zoster and postherpetic neuralgia: an evidence-based approach. J Fam Pract. 2012;61 Suppl 9:S9-S15.

24. Saks GM. Unmet need in the treatment of postherpetic neuralgia. Am J Manag Care. 2013;19 Suppl 1:S207-S213.

25. Klompas M, Kulldorff M, Vilk Y, Bialek SR, Harpaz R. Herpes zoster and postherpetic neuralgia surveillance using structured electronic data. Mayo Clin Proc. 2011;86(12):1146-1153.

26. Dubinsky RM, Kabbani H, El-Chami Z, Boutwell C, Ali H. Practice parameter: treatment of postherpetic neuralgia: an evidence-based report of the Quality Standards Subcommittee of the American Academy of Neurology. Neurology. 2004;63(6):959-965.

27. Dworkin RH, O'Connor AB, Audette J, et al. Recommendations for the pharmacological management of neuropathic pain: an overview and literature update. Mayo Clin Proc. 2010;85 (Suppl 3):S3-S14.

28. Attal N, Cruccu G, Baron R, et al. EFNS guidelines on the pharmacological treatment of neuropathic pain: 2010 revision. Eur J Neurol. 2010;17(9):1113-e88.

29. Rastogi R, Meek BD. Management of chronic pain in elderly, frail patients: finding a suitable, personalized method of control. Clin Interv Aging. 2013;8:37-46. 
30. Abdulla A, Adams N, Bone M, et al. Guidance on the management of pain in older people. Age Ageing. 2013;42 Suppl 1:11-i57.

31. Glauser TA, Salinas GD, Nevins H, Williamson JC, Wallace MS, Abdolrasulnia M. Communication gaps between physicians and patients with postherpetic neuralgia: results from a national study on practice patterns. J Pain Res. 2011;4:407-415.

32. Dworkin RH, Panarites CJ, Armstrong EP, Malone DC, Pham SV. Is treatment of postherpetic neuralgia in the community consistent with evidence-based recommendations? Pain. 2012;153(4):869-875.

33. Dworkin RH, Schmader KE. Treatment and prevention of postherpetic neuralgia. Clin Infect Dis. 2003;36(7):877-882.

34. Pickering G, Pereira B, Clere F, et al. Cognitive function in older patients with postherpetic neuralgia. Pain Pract. Epub May 23, 2013.

35. American Geriatrics Society Beers Criteria Update Expert Panel. American Geriatrics Society updated Beers Criteria for potentially inappropriate medication use in older adults. $J$ Am Geriatr Soc. 2012;60(4):616-631.

36. Labianca R, Sarzi-Puttini P, Zuccaro SM, Cherubino P, Vellucci R, Fornasari D. Adverse effects associated with non-opioid and opioid treatment in patients with chronic pain. Clin Drug Investig. 2012;32 Suppl 1:53-63.

37. Chou R, Fanciullo GJ, Fine PG, et al. Clinical guidelines for the use of chronic opioid therapy in chronic noncancer pain. $J$ Pain. 2009;10(2):113-130.

38. Merck. Varivax [prescribing information]. 2013. Available from: http:// www.merck.com/product/usa/pi_circulars/v/varivax/varivax_pi.pdf. Accessed January 15, 2014.

39. Merck. Zostavax [prescribing information]. 2006. Available from: http:// www.merck.com/product/usa/pi_circulars/z/zostavax/zostavax_pi2.pdf. Accessed January 15, 2014.

40. Oxman MN, Levin MJ, Johnson GR, et al. A vaccine to prevent herpes zoster and postherpetic neuralgia in older adults. $N$ Engl $J$ Med. 2005;352(22):2271-2284

41. Gagliardi AM, Gomes Silva BN, Torloni MR, Soares BG. Vaccines for preventing herpes zoster in older adults. Cochrane Database Syst Rev. 2012;10:CD008858.

42. Schmader KE, Oxman MN, Levin MJ, et al. Persistence of the efficacy of zoster vaccine in the shingles prevention study and the short-term persistence substudy. Clin Infect Dis. 2012;55(10):1320-1328.

43. Cohen EJ. Prevention of herpes zoster: we need to do better. JAMA Ophthalmol. 2013;131(3):396-398.

44. Javed S, Javed F, Mays RM, Tyring SK. Herpes zoster vaccine awareness among people $\geq 50$ years of age and its implications on immunization. Dermatol Online J. 2012;18(8):2.

45. Bruxelle J, Pinchinat S. Effectiveness of antiviral treatment on acute phase of herpes zoster and development of post herpetic neuralgia: review of international publications. Med Mal Infect. 2012;42(2):53-58.

46. GlaxoSmithKline Australia. Zovirax [prescribing information]. 2013. Available from: http://www.gsk.com.au/products_prescription-medicines_ detail.aspx?view=153. Accessed February 6, 2014.

47. Novartis. Famvir [prescribing information]. 2013. Available from: http:// www.pharma.us.novartis.com/product/pi/pdf/Famvir.pdf. Accessed February 3, 2014.

48. GlaxoSmithKline. Valtrex [prescribing information]. 2013. Available from: http://us.gsk.com/products/assets/us_valtrex.pdf. Accessed January 15, 2014.

Journal of Pain Research

\section{Publish your work in this journal}

The Journal of Pain Research is an international, peer-reviewed, open access, online journal that welcomes laboratory and clinical findings in the fields of pain research and the prevention and management of pain. Original research, reviews, symposium reports, hypothesis formation and commentaries are all considered for publication.
49. Wood MJ, Shukla S, Fiddian AP, Crooks RJ. Treatment of acute herpes zoster: effect of early $(<48 \mathrm{~h})$ versus late $(48-72 \mathrm{~h})$ therapy with acyclovir and valaciclovir on prolonged pain. J Infect Dis. 1998; 178 Suppl 1:S81-S84.

50. Lapolla W, Digiorgio C, Haitz K, et al. Incidence of postherpetic neuralgia after combination treatment with gabapentin and valacyclovir in patients with acute herpes zoster: open-label study. Arch Dermatol. 2011;147(8):901-907.

51. Han Y, Zhang J, Chen N, He L, Zhou M, Zhu C. Corticosteroids for preventing postherpetic neuralgia. Cochrane Database Syst Rev. 2013;3:CD005582.

52. Pfizer. Neurontin [prescribing information]. 2012. Available from: http://labeling.pfizer.com/ShowLabeling. aspx?id=630. Accessed January 15, 2014.

53. Backonja M, Glanzman RL. Gabapentin dosing for neuropathic pain: evidence from randomized, placebo-controlled clinical trials. Clin Ther. 2003;25(1):81-104.

54. Johnson P, Becker L, Halpern R, Sweeney M. Real-world treatment of post-herpetic neuralgia with gabapentin or pregabalin. Clin Drug Investig. 2013;33(1):35-44.

55. Depomed. Gralise [prescribing information]. 2012. Available from: http://www.gralise.com/lib/PDFS/GRALISE_PI.pdf. Accessed January 15, 2014.

56. XenoPort. Horizant [prescribing information]. Available from: http://www. horizant.com/docs/Horizant_PrescribingInformation.pdf. Accessed January 15, 2014.

57. Irving GA, Sweeney M. Tolerability and safety of gastroretentive oncedaily gabapentin tablets for the treatment of postherpetic neuralgia. J Pain Res. 2012;5:203-208.

58. Zhang L, Rainka M, Freeman R, et al. A randomized, double-blind, placebo-controlled trial to assess the efficacy and safety of gabapentin enacarbil in subjects with neuropathic pain associated with postherpetic neuralgia (PXN110748). J Pain. 2013;14(6):590-603.

59. Pfizer. Lyrica [prescribing information]. 2013. Available from: http://labeling.pfizer.com/ShowLabeling.aspx?id=561. Accessed January 15, 2014.

60. Endo. Lidoderm [prescribing information]. Available from: http:// www.endo.com/File\%20Library/Products/Prescribing\%20Information/ LIDODERM_prescribing_information.html. Accessed January 15, 2014.

61. Acorda Therapeutics. Qutenza [prescribing information]. Available from: http://www.qutenza.com/_docs/qutenza_full_PI_.pdf. Accessed January 15, 2014.

62. Saarto T, Wiffen PJ. Antidepressants for neuropathic pain: a Cochrane review. J Neurol Neurosurg Psychiatry. 2010;81(12):1372-1373.

63. Watson CP, Vernich L, Chipman M, Reed K. Nortriptyline versus amitriptyline in postherpetic neuralgia: a randomized trial. Neurology. 1998;51(4):1166-1171.

64. Watson CP, Tyler KL, Bickers DR, Millikan LE, Smith S, Coleman E. A randomized vehicle-controlled trial of topical capsaicin in the treatment of postherpetic neuralgia. Clin Ther. 1993;15(3):510-526.

65. Stempniak M. Closing the primary care gap. Hosp Health Netw. 2013;87(3):45-52.

66. Wolff K, Johnson R, Fitzpatrick TB. Fitpatrick's color atlas and synopsis of clinical dermatology. 5th Ed. New York; McGraw-Hill Education; 2005.

The manuscript management system is completely online and includes a very quick and fair peer-review system, which is all easy to use. Visit http://www.dovepress.com/testimonials.php to read real quotes from published authors. 